\title{
Formation of mullite thin film via a sol-gel process with polyvinylpyrrolidone additive
}

\author{
Yen-Yu Chen, Wen-Cheng J. Wei* \\ Institute of Materials Science and Engineering, National Taiwan University, 1 Roosevelt Road, Section 4, Taipei, 106 Taiwan, ROC
}

\begin{abstract}
Several tasks were tried to prepare crack-free mullite films on silica substrates. Basically, a sol containing TEOS (Tetraethylorthosilicate) and boehmite colloid was used for spin coating on silica substrate. The formulation of the sols was kept in stoichiometric composition $3 \mathrm{Al}_{2} \mathrm{O}_{3} \cdot 2 \mathrm{SiO}_{2}$, or contained a crack-limiting agent, Polyvinylpyrrolidone (PVP). These films were then treated up to $1300^{\circ} \mathrm{C}$. The properties of the sols and the dried films were characterized by rheometer, various thermal analysis techniques (DTA, TGA and TMA), also by XRD, SEM and TEM. The mullite film shows randomly oriented grains in sizes from $0.1 \mu \mathrm{m}$ to a few micrometers. The films still contain fine $\theta$ - and $\delta-\mathrm{Al}_{2} \mathrm{O}_{3}$ particles after being treated at $1280^{\circ} \mathrm{C}$ for $1 \mathrm{~h}$. C 2001 Elsevier Science Ltd. All rights reserved.
\end{abstract}

Keywords: Mullite; PVP; Sol-gel processes; Spin coating; Thin films

\section{Introduction}

Mullite, a high temperature ceramic material, can be synthesized from many methods, such as the reactions of $\mathrm{Al}_{2} \mathrm{O}_{3}$ with kaolinite, or pure silica with alumina compounds, chemical vapor deposition of $\mathrm{Al}$ and $\mathrm{Si}$ oxides, etc. According to the report by Schneider et al., ${ }^{1}$ the precursors of these routes can be classified into three types. "Type I" and "type III" precursors are amorphous in the as-prepared state and the former yields mullite as the only crystalline phase at about $980^{\circ} \mathrm{C}$, the later only partially transforms to $\mathrm{Al}-\mathrm{Si}$ spinel at about $980^{\circ} \mathrm{C}$. Mullite phase is formed above $\sim 1100^{\circ} \mathrm{C}$ and extensively at $1250^{\circ} \mathrm{C}$. "Type II" precursor contains pseudo-boehmite and non-crystalline $\mathrm{SiO}_{2}$ in the as-preparation state. Pseudoboehmite transforms to spinel phase above $\sim 400^{\circ} \mathrm{C}$ and to mullite above $\sim 1250^{\circ} \mathrm{C}$. In our previous report, ${ }^{2}$ a diphase gel consisted of type II precursors was prepared and characterized. TEOS in acidic and water rich environments forms silica sol with sizes around 20-40 nm. ${ }^{3}$ The ultimate mixture of nano-sized silica sol and pseudo-boehmite reduced the formation temperature of mullite as low as $1200^{\circ} \mathrm{C}$ in appropriate heat treatment condition. The mullitization occurs in accompany with a series transformation of transient alumina.

There are several reports ${ }^{4-7}$ mentioning the preparation of mullite thin film. The methods included dip coat-

* Corresponding author. Tel.: + 886-2-2363-2684; fax: + 886-2-2363. E-mail address:wjwei@ccms.ntu.edu.tw (W.-C.J. Wei). ing of a sol on silica substrate, ${ }^{4}$ by spin coating to form an unsupported film, ${ }^{5}$ spray pyrolyzing of a precursor on a $\mathrm{SiC}$ substrate, ${ }^{6}$ or CVD on a SiC substrate. ${ }^{7}$ There are some advantages of using sol-gel precursors to form thin film. However, the generation of crack is a problem, because the shrinkage during the drying and thermal stages induces stresses between the coating layer and substrate. To overcome this disadvantage, some additives were chosen, ${ }^{8-10}$ like a chelating agent or diols. The major effect of the additives to retard the condensation reaction and promote structural relaxation in the coated films. In the $\mathrm{BaTiO}_{3}$ material system, ${ }^{10}$ polyvinylpyrrolidone (PVP) additive was used effectively, increasing the thickness of the coating layer and decreasing the crack formation.

In the present study, a Type II sol was prepared and applied on a silica substrate by the spin coating method. The formulation was adjusted with the addition of the crack-sealing agent of PVP, in order to prevent crack formation. Thermal properties, including thermal shrinkage, thermogravimetric properties during heat treatment, and the microstructures of mullite were investigated.

\section{Experimental procedure}

\subsection{Preparation of the sample}

Tetraethylorthosilicate (TEOS, Art. 800658, MerckSchuchardt, Germany) and pseudo-boehmite colloids (Remal-A20, Remet, USA) were used as starting materials. 
Polyvinylpyrrolidone (PVP) with an average molecular weight of $1300 \mathrm{~K} \mathrm{~g} / \mathrm{mol}$ (Acrosorganics, USA) was used as the additive. For the preparation of a basic formulation (abb. TB), TEOS was first mixed with ethanol and hydrolyzed by deionized water under controlled acidic condition $(\mathrm{pH}=2.0)$ by $\mathrm{HCl}$ solution. After being fully hydrolyzed, the solution was mixed with pseudo-boehmite colloids and stirred for $1 \mathrm{~h}$.

The thin film sample was spin-coated on silica substrate (GE 124, General Electric, USA) at $5000 \mathrm{rpm}$ for $10 \mathrm{~s}$ and then dried at $25^{\circ} \mathrm{C}$ for $24 \mathrm{~h}$. After dried, the samples were heated to $600^{\circ} \mathrm{C}$ at a rate of $2^{\circ} \mathrm{C} / \mathrm{min}$, for dehydration and pyrolysis, and then heated to $1280^{\circ} \mathrm{C}$ for $1 \mathrm{~h}$. The processing steps of the other formulation containing PVP (abb. TBP) were the same as the TB, except the PVP solution was added in the partially hydrolyzed TEOS solution before it was mixed with pseudo-boehmite. The ratios of each component of the TB and TBP formulas are listed in Table 1. Due to the high viscosity of the PVP solution, the water needed for dilution and successful spin coating for TBP formulation was about 8 times higher than that of TB.

\subsection{Characterization}

The viscosity of sol was measured by a viscometer (DV-II, Brookfield Co., USA) at $25^{\circ} \mathrm{C}$. The thermal analysis was conducted with either differential thermal analysis (DTA), thermal gravimetric analysis (TGA, Du Pont Thermal Analyst 2000 series, USA), or thermal mechanical analysis (TMA, Setsys TMA16/18, Setram Co., USA). The heating rate was $10^{\circ} \mathrm{C} / \mathrm{min}$ for all TGA, DTA and TMA tests.

\subsection{Microstructure and phase observation}

Two scanning electron microscopes (SEM, Philip XL30 and Philip 515, Netherlands) and transmission electron microscope (TEM, Jeol CXII-100, Japan) were used to characterize the thickness and microstructure of the films in various heat-treatment stages. The grain size was also measured from the micrographs of TEM with a line-intercept method. The crystalline phases were also studied by X-ray diffractometry (XRD, PW1710, Philip Co., Netherlands).

Table 1

Formulation of two mullite precursors (in molar ratio) ${ }^{\mathrm{a}}$

\begin{tabular}{llllcl}
\hline & $\mathrm{SiO}_{2}$ & $\mathrm{Al}_{2} \mathrm{O}_{3}$ & $\mathrm{VP}$ & Water & Ethanol \\
\hline TB & 1 & 1.5 & 0 & 28 & 2.7 \\
TBP & 1 & 1.5 & 1 & 228 & 5 \\
\hline
\end{tabular}

a The sources of $\mathrm{SiO}_{2}, \mathrm{Al}_{2} \mathrm{O}_{3}$ and $\mathrm{VP}$ (vinylpyrrolidone) are TEOS, pseudo-boehmite and PVP (polyvinylpyrrolidone) respectively.

\section{Results and discussion}

\subsection{Thermal characters of gels}

When the precursors of diphasic mullite were dried and put to heat treatment, there could be a sequence of

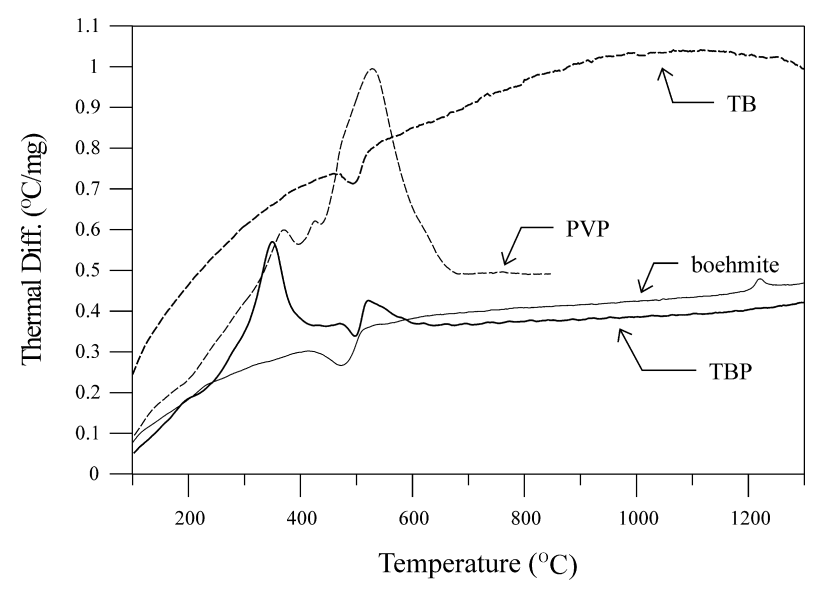

Fig. 1. DTA curves of as-dried TB, TBP, boehmite, and PVP, tested at a rate of $10^{\circ} \mathrm{C} / \mathrm{min}$.

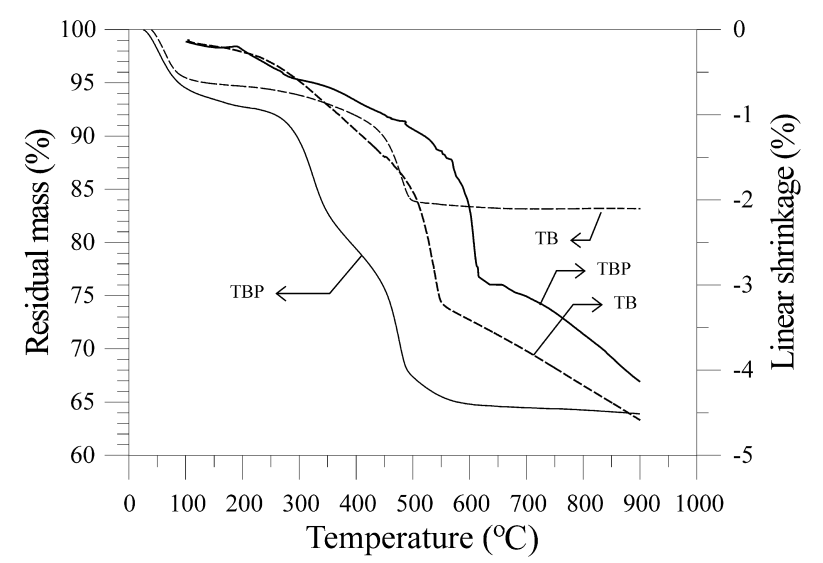

Fig. 2. TMA curves of TB and TBP formulations, tested at a rate of $10^{\circ} \mathrm{C} / \mathrm{min}$.

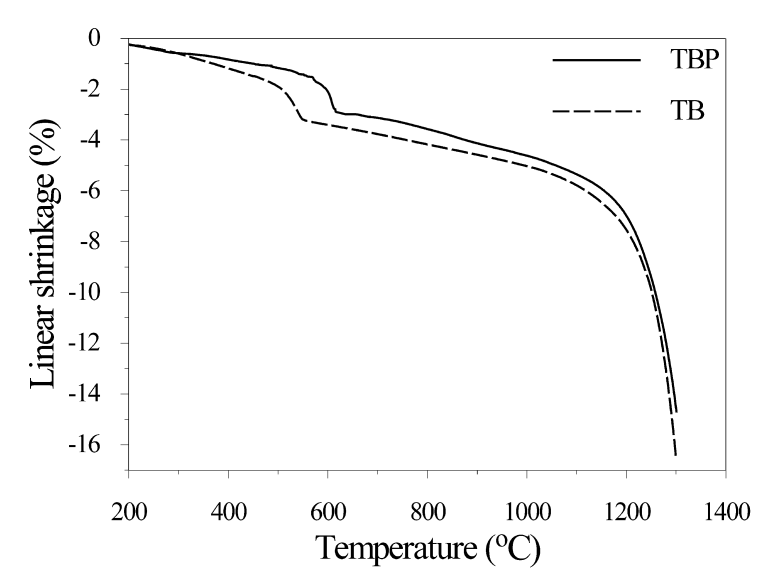

Fig. 3. TMA curves of TB and TBP samples. 
reactions taking place, e.g. dehydration and phase transformation. ${ }^{11}$ Fig. 1 shows the DTA curves of TB and TBP, as well as two pure materials, pseudo-boehmite and PVP. An endothermic peak appeared in TB curve at $480^{\circ} \mathrm{C}$. The peak, compared with the DTA curve of pure pseudo-boehmite, should be a dehydration reaction of pseudo-boehmite phase. However, reaction temperature in the precursory mixture is $20^{\circ} \mathrm{C}$ higher. The dehydra-

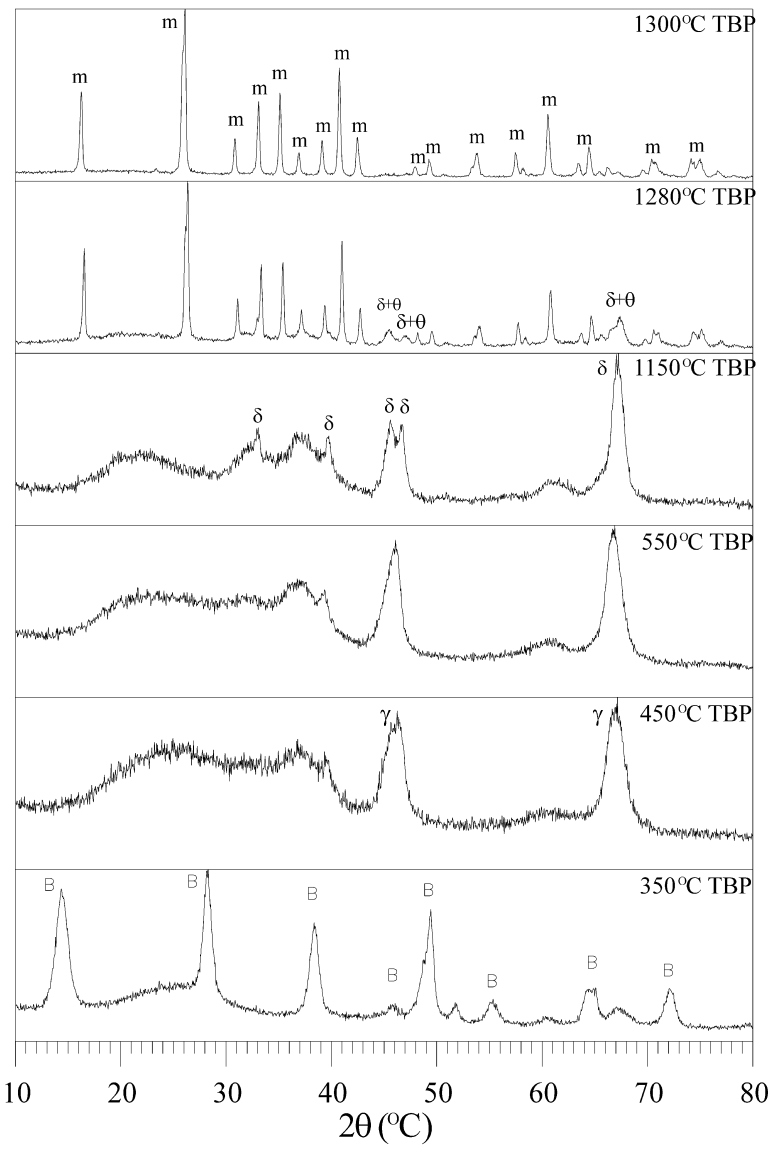

Fig. 4. XRD curves of TBP sample treated at specified temperature for $15 \mathrm{~min}$ at 350,450 and $550^{\circ} \mathrm{C}$ or $1 \mathrm{~h}$ at 1150,1280 and $1300^{\circ} \mathrm{C}$. (B : boehmite; $\gamma: \gamma-\mathrm{Al}_{2} \mathrm{O}_{3} ;$ m: mullite; $\delta: \delta-\mathrm{Al}_{2} \mathrm{O}_{3}, \theta: \theta-\mathrm{Al}_{2} \mathrm{O}_{3}$ ).

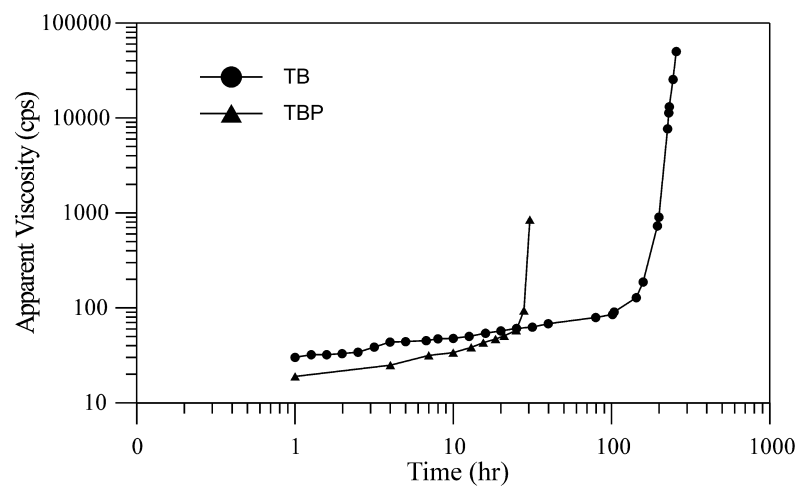

Fig. 5. Viscosity evolution of TB and TBP precursory sols at $25^{\circ} \mathrm{C}$. tion of pseudo-boehmite phase could be retarded by gel structure.

In the DTA curve of TBP, two exothermic peaks and one endothermic peak appeared. By knowing the thermal evolution of pure pseudo-boehmite and PVP, a large exothermic peak at about $350^{\circ} \mathrm{C}$ and a second exothermic peak of TBP at $520^{\circ} \mathrm{C}$ are due to the oxidation of PVP. This polymer is probably pyrolyzed with the catalytic effect by extremely fine $\mathrm{SiO}_{2}$ gel or $\mathrm{Al}_{2} \mathrm{O}_{3}$, resulting in low $M_{\mathrm{w}}$ PVP. Therefore, the DTA of partially dissociated PVP has different exothermic temperatures from that of as-received PVP. The endothermic
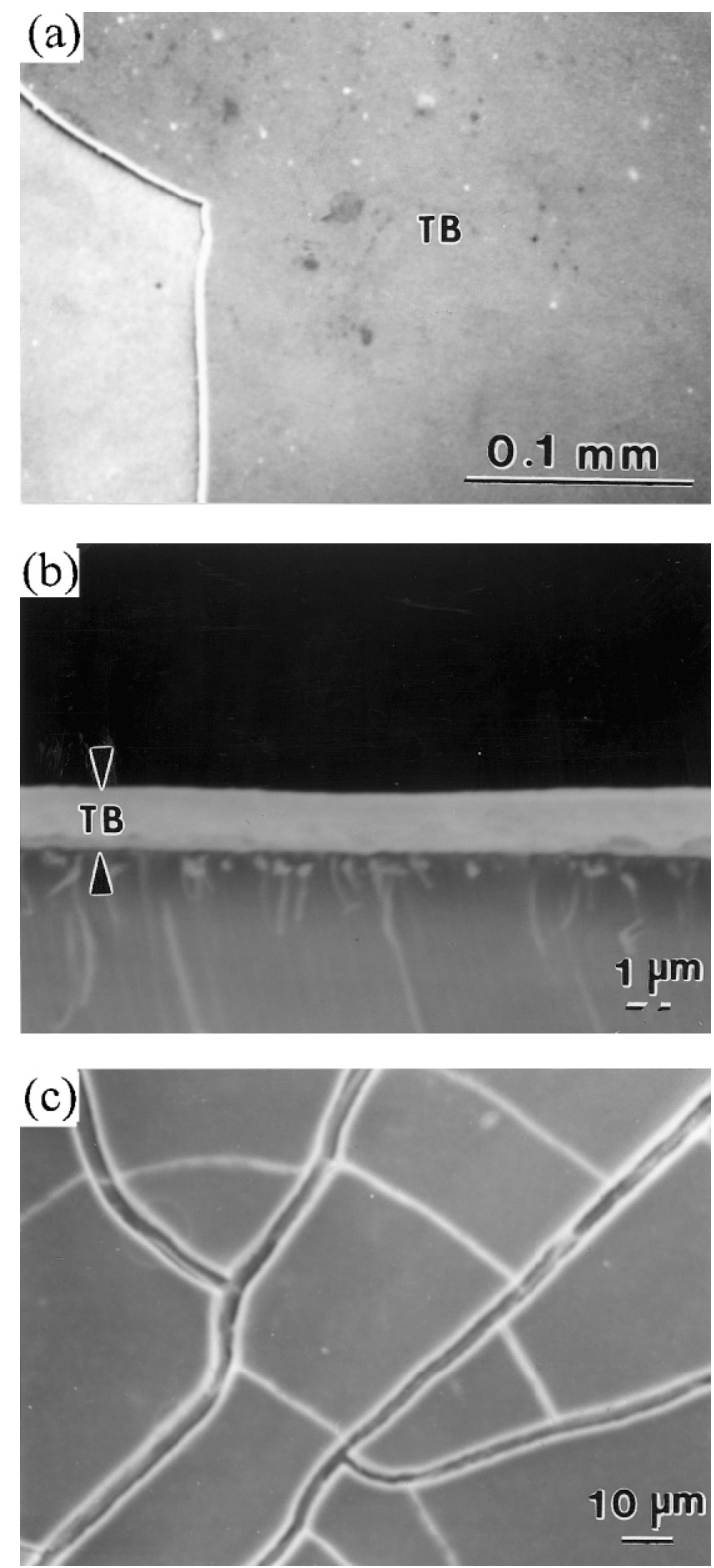

Fig. 6. SEM micrographs of thin film TB sample after $550^{\circ} \mathrm{C}$ heat treatment: (a) top-view, the right side is a gel layer and the lower left side is silica substrate; (b) cross-section, the thickness of the coating layer is about $1-2 \mu \mathrm{m}$; and (c) top-view of the sample sintered at $1280^{\circ} \mathrm{C}$. 
peak of curve the TBP at $490^{\circ} \mathrm{C}$ is similar to the one in TB curve, representing the dehydration of boehmite as well.

Fig. 2 shows the TGA and TMA results of TB and TBP samples below $900^{\circ} \mathrm{C}$. The TGA curve of $\mathrm{TB}$ is shown continuously losing mass until $420^{\circ} \mathrm{C}$. The loss rate is then accelerated to $500^{\circ} \mathrm{C}$. Above $500^{\circ} \mathrm{C}$, the mass remains nearly constant. The TGA results of the TBP sample with PVP are different from the TB sample. The TBP gel shows three steps of mass loss. The first occurs below $100^{\circ} \mathrm{C}$. It is the drying of volatile $\mathrm{H}_{2} \mathrm{O}$ and ethanol solution. The second mass loss is at about $250-350^{\circ} \mathrm{C}$ representing the burn out of some low $M_{\mathrm{w}} \mathrm{PVP}$, and the dehydration of silica gel. The third step started at about $450^{\circ} \mathrm{C}$ and ended about $580^{\circ} \mathrm{C}$ is the burned-out of the rest of PVP and complete dehydration of pseudo-boehmite. The total mass loss of TBP is ca. $36 \%$ higher than that of $16.5 \%$ for TB.

Part of Fig. 2 and the whole of Fig. 3 show the TMA curves of TB and TBP samples. Both have two major shrinking stages. The first shrinkage of the curve TB is at about $500-540^{\circ} \mathrm{C}$ and the second starts from $1050^{\circ} \mathrm{C}$. Note that the first shrinkage of curve TBP, as shown in Fig. 2, occurs $80^{\circ} \mathrm{C}$ higher than that of TB curve. The second shrinkage temperature started at $1080^{\circ} \mathrm{C}$ is also higher than the shrinkage of TB. The distinct difference of the shrinkage may be due to the response for a better performance of the TBP sample at higher temperature.

The samples shrink ca. $\leqslant 1.5 \%$ near $500^{\circ} \mathrm{C}$ for $\mathrm{TB}$ or $580^{\circ} \mathrm{C}$ for TBP. Both first shrinkage of the TB and TBP are starting at the end of mass loss of their TGA curves. That is possible due to the densification of silica gel or $\gamma-\mathrm{Al}_{2} \mathrm{O}_{3}$ grains, or the rearrangement of those fine grains. But the results determined by quantitative XRD can only reveal the evidence of the former case, which show grain growth of $\gamma-\mathrm{Al}_{2} \mathrm{O}_{3}$ in the temperature region $500-580^{\circ} \mathrm{C}$. It is shown that the width of the X-ray diffraction peak $\left(2 \theta=67^{\circ}\right)$ of $\gamma$-phase at $550^{\circ} \mathrm{C}$ in Fig. 4 is reduced compared to that at $450^{\circ} \mathrm{C}$. The $\gamma-\mathrm{Al}_{2} \mathrm{O}_{3}$ particles grow to a larger size, therefore, narrow down the peak width as well as that of TBP. However, the rearrangement behavior of both phases can not be investigated by present techniques.

Systematical XRD analysis was also carried out to identify the phase evolution of the precursory gels. At these characteristic thermal temperatures of the TBP sample, including $350,450,550,1150,1280$ and $1300^{\circ} \mathrm{C}$, the samples were analyzed. When heated at $350^{\circ} \mathrm{C}$ for 15 min, the crystalline phase of the sample is still boehmite. At $450^{\circ} \mathrm{C}$, part of the boehmite is transformed to $\gamma-\mathrm{Al}_{2} \mathrm{O}_{3}$. At $550^{\circ} \mathrm{C}$, the boehmite phase is gone, but transformed to $\gamma-\mathrm{Al}_{2} \mathrm{O}_{3}$. At $1150^{\circ} \mathrm{C}$, the $\delta$ - and $\theta-\mathrm{Al}_{2} \mathrm{O}_{3}$
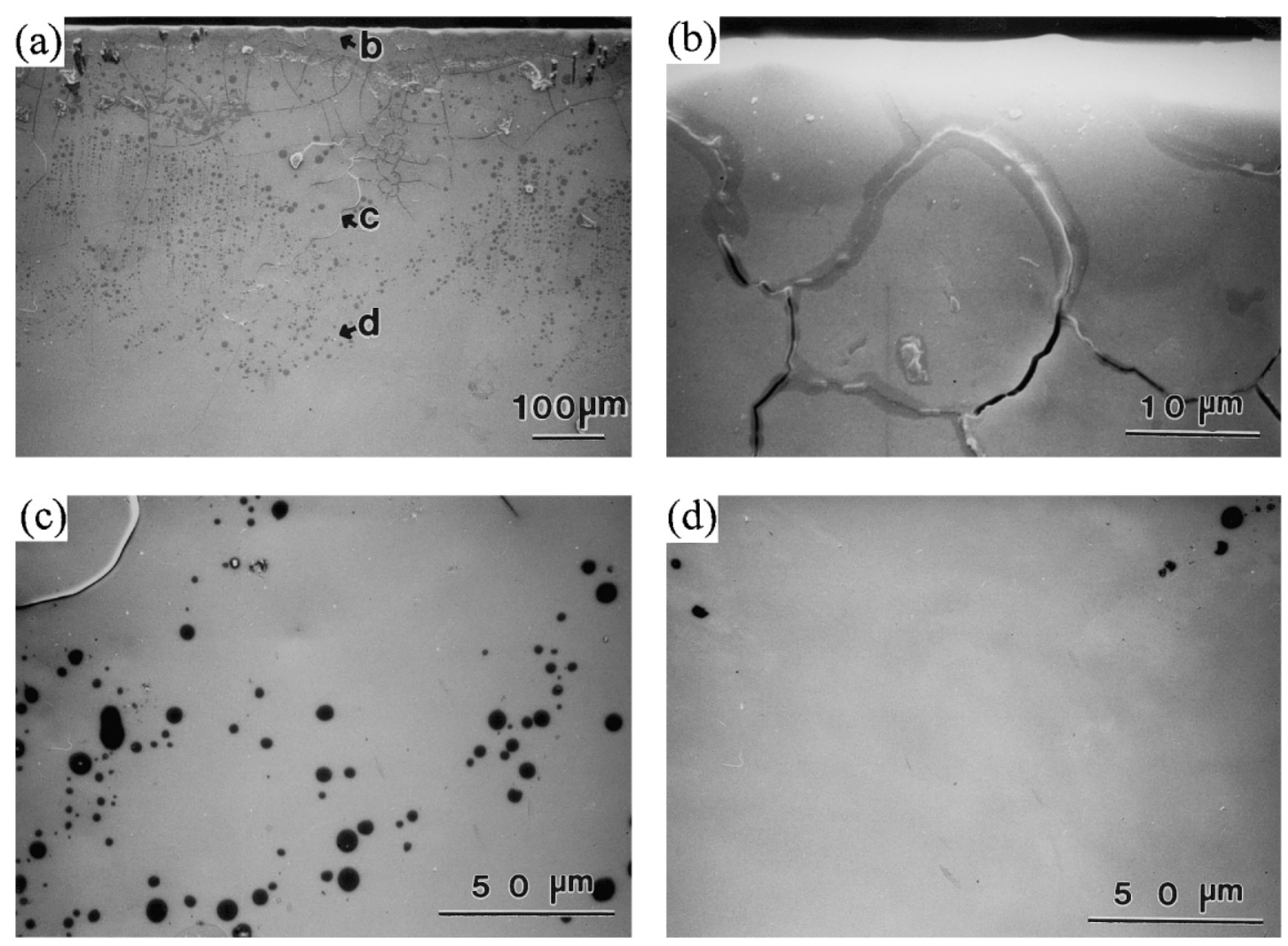

Fig. 7. SEM micrographs of TBP film after $1280^{\circ} \mathrm{C}$ heat treatment and held for $1 \mathrm{~h}$ (a) at low magnification (b), (c) and (d) at higher magnification. 
are found in the samples, but the relative quantity of them is not able to differentiated by XRD. At $1280^{\circ} \mathrm{C}$, the mullite phase is identified with a minor $\mathrm{Al}_{2} \mathrm{O}_{3}$ phase. At $1300^{\circ} \mathrm{C}$, the mullite is the major crystalline phase and the other crystalline phases are rarely found.

Similar to the phase evolution of TB, the TBP sample with PVP (Fig. 4) contains boehmite and amorphous $\mathrm{SiO}_{2}$ phase while at temperatures lower than $420^{\circ} \mathrm{C}$. But the former changes to $\gamma$-phase as the temperature raised. The volatile groups (-OR or $\mathrm{OH})$ on $\mathrm{SiO}_{2}$ gel ${ }^{1}$ and dehydration of boehmite phase ${ }^{11}$ are losing mass below $500^{\circ} \mathrm{C}$. It is believed that the shrinkage at $580^{\circ} \mathrm{C}$ is due to the sintering of ultrafine $\gamma-\mathrm{Al}_{2} \mathrm{O}_{3}$ as well. In addition to the small shrinkage at $580^{\circ} \mathrm{C}$, a second shrinkage starting from 1070 to $1300^{\circ} \mathrm{C}$, in a larger scale of $12 \%$, is noted for TBP sample. Two major $\mathrm{Al}_{2} \mathrm{O}_{3}$ transformations, boehmite to $\gamma-\mathrm{Al}_{2} \mathrm{O}_{3}$ and $\delta$ - and $\theta-\mathrm{Al}_{2} \mathrm{O}_{3} / \mathrm{SiO}_{2}$ to mullite, are in associated with shrinkage of the diphasic samples.

\subsection{Characterization of thin film coating}

The viscosity of two diphasic sols is shown in Fig. 5, The basic formulation (TB), which aged at $25^{\circ} \mathrm{C}$, would increase its viscosity in $150 \mathrm{~h}$. The gelation point $\left(\mathrm{T}_{\mathrm{g}}\right)$ of the sol is $150 \mathrm{~h}$ at which is the last chance to do a spin coating. Inappropriate usage of sol may induce cracking or ripple surface. The second formulation, TBP, which has a water/ethanol ratio 45.6:1, would have a lower viscosity $(\sim 10 \mathrm{cps})$ at starting point and gradually increase its viscosity until gelling. The gelation point of TBP shows a viscosity ca. $50 \mathrm{cps}$ at $25 \mathrm{~h}$. The coating of the sols is always conducted while the viscosity is less than $100 \mathrm{cps}$ for TB and $50 \mathrm{cps}$ for TBP.

Fig. 6 is a series of SEM micrographs illustrating the surface texture of the TB films originally coated on silica plate. The as-coated film started with a lowerviscosity ( $32 \mathrm{cps}$ ) sol shows no cracks. The cross-section of the film reveals the thickness of ca. 1-2 $\mu \mathrm{m}$. The film was in the condition without being cracking after calcined at $600^{\circ} \mathrm{C}$ for $0.5 \mathrm{~h}$. However, the film cracks to mosaic texture while sintered at $1280^{\circ} \mathrm{C}$ [Fig. 6(c)].

If the formulation of sol changes to TBP, the coated mullite will show better intactness (Fig. 7). The thickness of the layer is also around 1-2 $\mu \mathrm{m}$. But near the edge of the $\mathrm{SiO}_{2}$ substrate, there still have some cracks and some bubbles observed next to the region of cracks. The rest of the film is free from cracking.

\subsection{Microstructural characterization}

Fig. 8 is a set of TEM micrographs of the TBP thin film of formulation sintered at $1280^{\circ} \mathrm{C}$ for $1 \mathrm{~h}$. The grain boundary of the mullite grain is very wavy which is the typical nature of diphasic mullite. The grain boundaries of the mullite are still irregular, implying that the reaction of residual $\mathrm{Al}_{2} \mathrm{O}_{3}$ grains $(\sim 20-50 \mathrm{~nm})$ with the
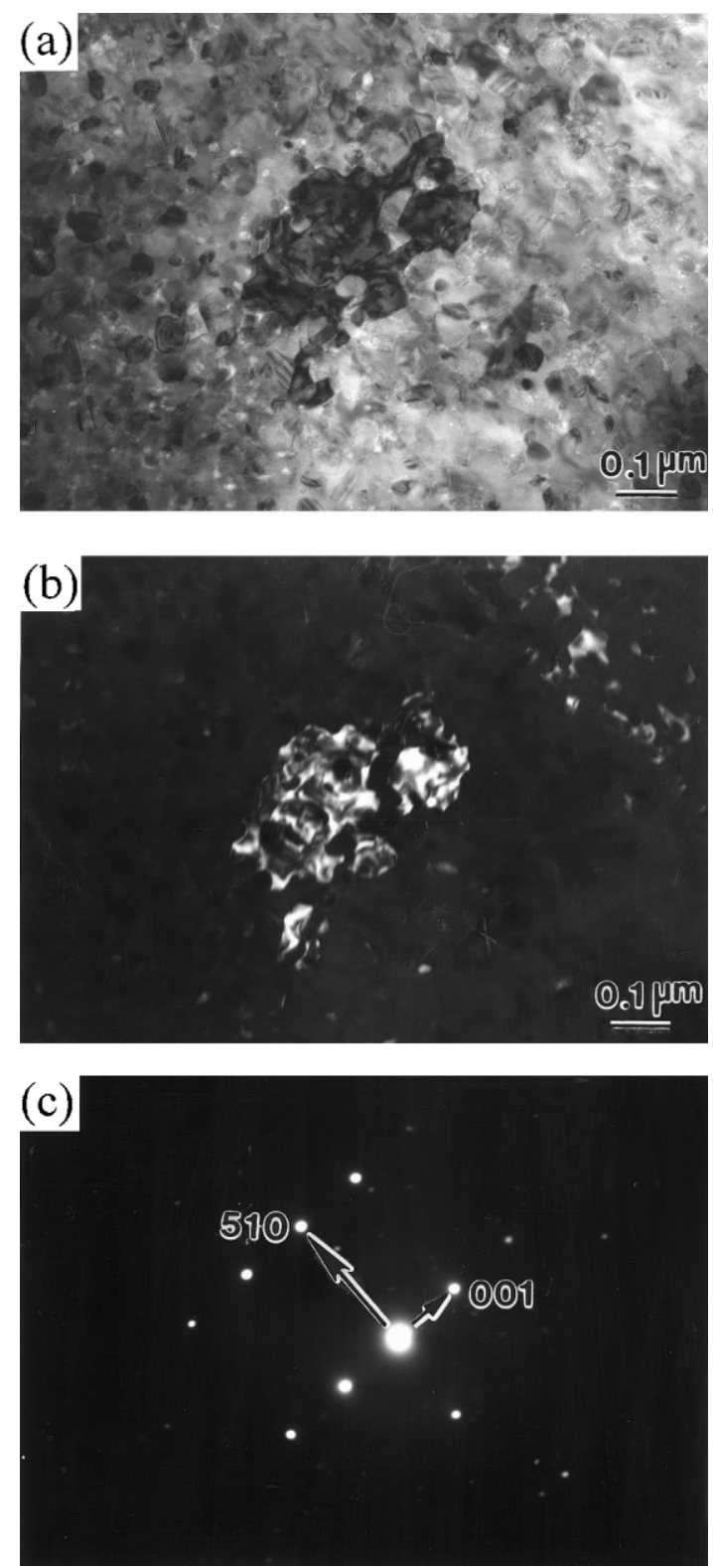

Fig. 8. TEM micrographs of TBP thin film, (a) BF, (b) CDF of (a), (c) DP of the center grain in (a).

mullite is not finished yet. The interior of the mullite still contains some of residual $\mathrm{Al}_{2} \mathrm{O}_{3}$ grains and pores. That is consistent with our previous observation on bulky diphasic gel. ${ }^{2}$ But most of the mullite are larger than 0.5 $\mu \mathrm{m}$ and grow in the range of $0.5-5 \mu \mathrm{m}$ with random orientation, which is proven with the observation of the zone axis of numerous grains. Fig. 9 shows some larger grains on the film near the $\mathrm{SiO}_{2}$ substrate. The grains are mullite crystals, but appear abnormal acicular in morphology with a long axis oriented parallel to the [001] direction. The abnormal grain growth of mullite is possible due to the melting of silica substrate. The phase offered a favor route for atomic transport during sintering. The grain shape of mullite is plate-like and detailed analysis is needed for further investigation. 

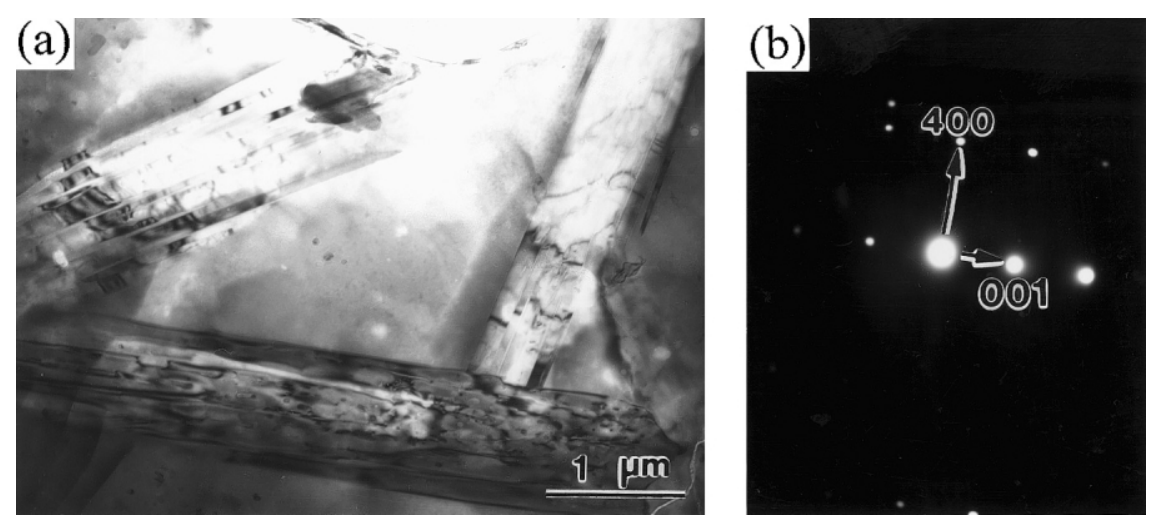

Fig. 9. Abnormal grain growth of mullite on TBP film (a) BF, (b) DP. The grains are grown along the direction [001].

\section{Conclusion}

PVP is an effective crack-sealing agent for the formation of thin diphasic mullite film. The thermal behavior of TBP is similar to that of TB, besides the burnout of PVP below $600^{\circ} \mathrm{C}$ and the delay of dehydration reactions. The mullite phase appears at temperatures above $1280^{\circ} \mathrm{C}$. Minor residue of $\mathrm{Al}_{2} \mathrm{O}_{3}$ in mullite grains are found if held at $1300^{\circ} \mathrm{C}$ for less than $1 \mathrm{~h}$. Uniform film prepared from the TBP sol can be obtained after sintering to $1280^{\circ} \mathrm{C}$. The mullite grain morphologies of thin film (TBP) samples are equiaxial, but may grow to platy shape with a plane parallel to the direction [001] of mullite crystal. The grains in thin film are all in sizes around submicrometer to micrometer and randomly oriented, which are similar to the microstructural features of a bulky mullite sample.

\section{Acknowledgements}

The authors would like to thank the funding given by National Science Council (NSC) in Taiwan under grant number NSC89-2216-E-002-043.

\section{References}

1. Schneider, H., Saruhan, B. and Voll, D., Mullite precursor phases. J. Eur. Ceram. Soc., 1993, 11, 87-94.
2. Wei, W. J. and Halloran, J. W., Phase transformation of diphase aluminosilicate gels. J. Am. Ceram. Soc., 1988, 71, 166-172.

3. Wei, W. J., Processing and microstructure evolution of silica sols and gels. Bulletin of the College of Engineering N.T.U., 1991, 53, 9-22.

4. Okada, K. and Otsuka, N., Preparation of transparent mullite films by dip coating method, mullite and mullite matrix composites. Am. Ceram. Soc. Inc, 425-434.

5. Huling, J. C. and Messing, G. L., A Method for preparation of unsupported sol-gel thin films. J. Am. Ceram. Soc., 1988, 74, C-222-C-224.

6. Braue, W., Paul, G., Schneider, H. and Decker, J., In-plane microstructure of plasma-sprayed $\mathrm{Mg}-\mathrm{Al}$ spinel and 2/1-mullite based protective coatings: an electron microscopy study. J. Eur. Ceram. Soc., 1996, 16, 85-97.

7. Haynes, J. A., Lance, M. H., Cooley, K. M., Ferber, M. K., Lowden, R. A. and Stintion, D. P., CVD mullite coatings in hightemperature, high-pressure air- $\mathrm{H}_{2} \mathrm{O} . J$. Am. Ceram. Soc., 2000, 83, 657-659.

8. Okubo, T., Tahahashi, T., Sadakata, M. and Nagamoto, H., Crack-free porous YSZ membrane via controlled synthesis of zirconia sol. J. Membrane Sci., 1996, 118, 151-157.

9. Pardo, L., Calzada, M. L., Milne, S. J., Ricote, J. and Jimenez, B., Microstructure development of diol-based sol-gel processes lead titanate thin film. J. Phys. Chem. Solids, 1995, 56, 15-25.

10. Kozuka, H. and Kajimura, M., Single-step dip coating of crackfree $\mathrm{BaTiO}_{3}$ films $>1 \mu \mathrm{m}$ thick: effect of poly(vinylpyrrolidone) on critical thickness. J. Am. Ceram. Soc., 2000, 83, 1056-1062.

11. Padmaja, P., Anikumar, G. M. and Warrier, K. G. K., Formation of mullite phase in diphase gels consisting of TEOS and boehmite with and without dehyfroxylation. J. Eur. Ceram. Soc., 1998, 18, 1765-1769. 